Hasil tabulasi silang menunjukkan bahwa responden dengan perilaku 5 responden dengan perilaku vulva hygiene baik, dan semuanya (100\%) tidak mengalami gejala servisitis. Responden dengan perilaku vulva hygiene cukup terdapat 41 orang, 85,4\% diantaranya tidak mengalami Servisitis. Sedangkan responden dengan perilaku vulva hygiene kurang baik terdapat $77,8 \%$ yang mengalami gejala servisitis.

Perilaku vulva hygiene yang kurang baik beresiko terhadap terjadinya servisitis. Servisitis berpotensi mengancam setiap wanita karena setiap bulan wanita mengalami menstruasi yang dapat membuat organ kewanitaan menjadi lembab dan mudah untuk terinfeksi, terutama jika yang bersangkutan tidak dapat menjaga kebersihan dirinya, seperti pemberian pembalut yang kurang sesuai, cara membersihkan dan mencuci yang kurang tepat dan sebagainya.

Responden pasti mengeluarkan biaya untuk memenuhi kebutuhan perawatan vulva tersebut, dan hal ini menjadi kendala bagi responden dengan kemampuan sosial ekonomi yang terbatas. Data menunjukkan bahwa responden yang mengalami servisitis adalah responden yang bekerja mengurus rumah tangga (IRT) dan yang bekerja sebagai pegawai swasta (penjaga toko, karyawan koperasi, dll), karena kebanyakan IRT tidak mendapatkan gaji, demikian pula dengan pegawai swasta di daerah ini banyak yang masih di bawah UMR. Sementara responden yang bekerja sebagai guru (PNS) dan wiraswasta (pedagang) tidak ada yang mengalami servisitis.

Sesuai dengan pendapat Perry dan Potter (2005) bahwa sumber daya ekonomi seseorang mempengaruhi jenis dan tingkat praktik kebersihan yang digunakan. Petugas harus menentukan apakah individu dapat menyediakan bahan-bahan yang penting seperti deodoran, sampo, pasta gigi, dan kosmetik. Petugas juga harus menentukan jika penggunaan dari produk-produk ini merupakan bagian dari kebiasaan sosial yang dipraktikan oleh kelompok sosial pasien.

Wanita bekerja (wanita karir) juga cenderung menjaga citra tubuh agar dapat tampil prima di hadapan pelanggannya. Citra tubuh yang ideal bagi responden telah mendorong mereka untuk menjaga penampilan dengan melakukan perawatan diri, termasuk perawatan vulva hygiene, agar tidak mengganggu pekerjaan dan meningkatkan rasa percaya dirinya.

Sesuai dengan pendapat Perry dan Potter (2005) bahwa penampilan umum individu dapat menggambarkan pentingnya Hygiene pada orang tersebut. Citra tubuh merupakan konsep subjektif seseorang tentang penampilan fisiknya. Citra tubuh ini dapat seringkali berubah. Dan mempengaruhi cara mempertahankan hygiene.

Vulva hygiene yang baik dipengaruhi oleh status sosial ekonomi seseorang dan citra diri. Vulva higeine yang kurang baik beresiko terhadap terjadinya servisitis. Artinya, perilaku vulva hygiene secara nyata berpengaruh terhadap kejadian servisitis, dengan didukung oleh faktor-faktor lain yang mempengaruhi vulva hygiene seperti status sosial ekonomi dan citra diri.

\section{KESIMPULAN}

Berdasarkan hasil penelitian hubungan antara Vulva hygiene dengan kejadian servisitis di Desa Sambigede Kecamatan Sumberpucung Kabupaten Malang, dapat ditarik kesimpulan sebagai berikut :

1. Perilaku vulva hygiene pada wanita usia subur di Desa Sambigede Kecamatan Sumberpucung Kabupaten Malang sebanyak 28,1\% kurang baik.

2. Kejadian servisitis pada WUS di Desa Sambigede Kecamatan Sumberpucung Kabu-paten Malang sebesar $31,2 \%$

3. Ada hubungan yang signifikan antara Vulva hygiene dengan kejadian servisitis di Desa Sambigede Kecamatan Sumberpucung Kabupaten Malang, dengan taraf signifikansi $=0,000$.

\section{DAFTAR PUSTAKA}

Kholida. 2008 Perawatan Diri Saat Haid. http:// sangkhaleed.blogspot.com/2008/05/ perawatan-diri-saat-haid.html. Sitasi tanggal 29 Mei 2011

Manuaba, IAC, dkk. (2010). Ilmu Kebidanan, Penyakit Kandungan dan KB untuk Pendidikan Bidan, Edisi 2. Jakarta : EGC.

Manuaba, IAC, dkk. (2009). Memahami Kesehatan Reproduksi Wanita, Edisi 2. Jakarta : EGC.

Notoatmodjo, S. (2007). Promosi Kesehatan dan Ilmu Perilaku. Cetakan I. PT. Rineka Cipta, Jakarta.

Notoatmodjo, S. (2007). Kesehatan Masyarakat, Ilmu dan Seni. Jakarta : Rineka Cipta.

Potter \& Perry. (2005). Buku Ajar Fundamental Keperawatan: Konsep, proses dan praktik. Jakarta : EGC.

Prawirohardjo, Sarwono, (2002). Ilmu Kebidanan, Jakarta: YBP.SP

Tarwoto \&Wartonah. (2010). Kebutuhan Dasar Manusia dan Proses Keperawatan. Jakarta:Salemba Medika. 
Sesuai dengan pendapat Kholida (2009) bahwa wanita perlu menjaga kebersihannya, mengganti pembalut secara teratur sebanyak minimal 5-6 kali sehari atau tiap 5 jam sekali atau bila dirasa perlu. Memilih pembalut yang daya serapnya tinggi, tidak mengandung zat kimia berbahaya, tidak menyebabkan iritasi pada kulit, dan sebisa mungkin merapikan bulu kemaluan agar darah tidak banyak yang menempel di sekitar vagina, sehingga rentan akan infeksi atau iritasi. Memotong kuku dengan rapi, serta mencuci tangan sebelum menyentuh daerah kemaluan. Serta menghindari menyentuh bagian dalam kemaluan terutama ketika sedang haid. Servisitis juga terjadi secara menahun yang dicetuskan oleh luka akibat proses persalinan. menahun dijumpai pada sebagian besar wanita yang pernah melahirkan.

Prawirohardjo (2002) juga menyatakan bahwa servisitis atau radang pada serviks uteri terjadi pada sebagaian besar wanita terutama yang pernah melahirkan dan menjadi infeksi menahun yang sering tanpa disertai gejala-gejala atau keluhan yang jelas dari infeksi yang bersangkutan. Servisitis baru diketahui setelah dilakukan pemeriksaan yaitu porsio tampak kemerahan yang tidak dipisahkan secara jelas dari epitel porsio di sekitarnya, sekret yang dikeluarkan terdiri atas mukus bercampur nanah atau bahkan kadang-kadang serviks kelihatan normal dan baru diketahui setelah dilakukan pemeriksaan mikroskopik yaitu ditemukan infiltrasi leukosit dalam stroma endoserviks.

Tabel 4

Tabulasi Silang Antara Vulva hygiene dengan Terjadinya Servisitis

\begin{tabular}{lllccc}
\hline & & \multicolumn{3}{c}{ Servisitis } & \\
& & Positif & Negatif & Total \\
\hline Vulva hygiene & Baik & Jumlah & 0 & 5 & 5 \\
& & $\%$ & $.0 \%$ & $100.0 \%$ & $100.0 \%$ \\
& \multirow{4}{*}{ Cukup } & Jumlah & 6 & 35 & 41 \\
& & $\%$ & $14.6 \%$ & $85.4 \%$ & $100.0 \%$ \\
& \multirow{2}{*}{ Kurang } & Jumlah & 14 & 4 & 18 \\
& & $\%$ & $77.8 \%$ & $22.2 \%$ & $100.0 \%$ \\
\hline Total & & Jumlah & 20 & 44 & 64 \\
& & $\%$ & $31.2 \%$ & $68.8 \%$ & $100.0 \%$ \\
\hline
\end{tabular}

Dengan demikian responden yang sering melahirkan beresiko mengalami servisitis lebih tinggi dibandingkan dengan yang belum pernah atau jarang melahirkan. Data hasil penelitian menunjukkan bahwa ada peningkatan kasus servisitis setelah wanita melahirkan yang ke 2 dan seterusnya. Data tabulasi silang menunjukkan bahwa responden yang memiliki 2 anak beresiko sebanyak $39,1 \%$ dan yang mempunyai 3 anak beresiko $50 \%$ bahkan yang melahirkan 4 anak beresiko sebesar $66,7 \%$.

Sesuai dengan pendapat Manuaba (2010) bahwa servisitis dapat disebabkan oleh persalinan dimana terdapat invasi stafilokokus dan streptokokus. Servisitis yang akut banyak dijumpai pada infeksi hubungan seksual sedangkan yang
Dari tabel di atas diketahui bahwa terdapat 5 responden dengan perilaku vulva hygiene baik, dan semuanya $(100 \%)$ tidak mengalami gejala servisitis. Responden dengan perilaku vulva hygiene cukup terdapat 41 orang, 35 diantaranya $(85,4 \%)$ tidak mengalami Servisitis. Sedangkan responden dengan perilaku vulva hygiene kurang baik terdapat 18 orang, dan 14 diantaranya $(77,8 \%)$ mengalami gejala servisitis.

Hasil analisa statistik didapatkan bahwa nilai Chi-Square $\left(\mathrm{X}^{2}\right)$ sebesar 25.679 dan taraf signifikansi $=0,000$ lebih kecil dari a yang ditetapkan sebesar 0,05 , sehingga $\mathrm{H}_{0}$ ditolak dan bisa disimpulkan ada hubungan yang bermakna antara vulva hygiene dengan terjadinya servisitis. 


\section{HASIL DAN PEMBAHASAN}

Tabel 2 menunjukkan bahwa sebagian besar yaitu 41 responden $(64,1 \%)$ memiliki perilaku vulva hygiene yang cukup dan sebagian kecil yaitu 5 responden $(7,8 \%)$ memiliki perilaku vulva hygiene yang baik.

Hasil penelitian menunjukkan bahwa sebagian besar responden $(71,9 \%)$ memiliki perilaku vulva hygiene yang cukup dan baik dan sebagian kecil responden $(28,1 \%)$ memiliki perilaku vulva hygiene kurang baik. Vulva hygiene sebagian besar responden sudah cukup baik karena responden memperhatikan kesehatannya melalui perawatan diri sehari-hari.

Sesuai dengan pendapat Tarwoto dan Wartonah (2010), bahwa dalam kehidupan sehari-hari kebersihan merupakan hal yang sangat penting dan harus diperhatikan karena kebersihan akan mempengaruhi kesehatan dan psikis seseorang. Kebersihan itu sendiri sangat dipengaruhi oleh nilai individu dan kebiasaan. Jika seseorang sakit, biasanya masalah kebersihan kurang diperhatikan, hal ini terjadi karena kita menganggap masalah kebersihan adalah masalah sepele, padahal jika hal tersebut dibiarkan terus dapat mempengaruhi kesehatan secara umum.

Sedangkan responden dengan perilaku vulva hygiene yang masih kurang baik bisa dipengaruhi oleh faktor pendidikannya. Hasil penelitian menunjukkan bahwa responden yang berpendidikan SD terdapat 10 orang, 8 diantaranya $(80 \%)$ memiliki perilaku vulva hygiene kurang baik. Responden yang berpendidikan SLTP ter-dapat 28 orang, 19 diantaranya $(67,9 \%)$ memiliki perilaku vulva hygiene cukup baik, sedangkan responden yang berpendidikan SLTA terdapat 24 orang, 23 diantaranya $(95,8 \%)$ memiliki perilaku vulva hygiene cukup dan baik. Demikian juga dengan responden yang berpendidikan sarjana, semuanya memiliki perilaku vulva hygiene cukup dan baik.
Dari faktor pekerjaan dan usia dalam penelitian ini tidak terlihat banyak berperan mempengaruhi perilaku vulva hygiene responden, karena proporsi responden yang mempunyai perilaku vulva hygiene kurang baik hampir berimbang antara pekerjaan 1 dengan pekerjaan lainnya, dan hasil ini juga dipengaruhi oleh terbatasnya jenis pekerjaan yang berhasil diidentifikasi, yang mana sebagian besar adalah mengurus rumah tangga. Namun pada prinsip-nya pekerjaan seseorang tetap mempengauhi perilaku kesehatannya, karena merupakan indi-kator atau karakteristik sosial budaya yang melekat pada diri seseorang.

Hasil penelitian ini sesuai dengan pendapat Notoatmodjo (2007), bahwa faktor eksternal yakni lingkungan, baik lingkungan fisik, sosial, budaya, ekonomi, politik dan sebagainya. Faktor lingkungan ini sering merupakan faktor yang dominan yang mewarnai perilaku seseorang. Purwanto (2008) juga mengungkapkan bahwa lingkungan sebagai faktor yang berpengaruh bagi pengembangan sifat dan perilaku individu mulai mengalami dan mengecap alam dan sekitarnya. Dengan lingkungan dapat pengaruh mempengaruhi perilaku manusia sehingga kenyataannya akan menuntut suatu keharusan sebagai makhluk sosial yang dalam keadaan bergaul satu dengan yang lainnya.

Hasil penelitian menunjukkan bahwa sebagian besar responden (68,8\%)tidak mengalami Servisitis, dan sebanyak $31,2 \%$ responden mengalami Servisitis. Gejala servisitis yang terjadi pada responden antara lain pembengkakan mulut rahim dan terlihat merah karena tanda-tanda infeksi atau ada iritasi. Servisitis memang rawan mengancam setiap wanita karena setiap bulan wanita mengalami menstruasi yang dapat membuat organ kewanitaan menjadi lembab dan mudah untuk terinfeksi, terutama jika yang bersangkutan tidak dapat menjaga kebersihan dirinya, seperti pemberian pembalut yang kurang sesuai, cara membersihkan dan mencuci yang kurang tepat dan sebagainya.

Tabel 3

Kejadian Servisitis pada Responden di Desa Sambigede Kecamatan Sumberpucung Kabupaten Malang

\begin{tabular}{llll}
\hline No. & Kejadian Servisitis & Frekuensi & Prosentase (\%) \\
\hline 1 & Positif & 20 & 31.2 \\
2 & Negatif & 44 & 68.8 \\
\hline Total & 64 & 100 \\
\hline
\end{tabular}


Tabel 1

Variabel Penelitian

\begin{tabular}{|c|c|c|c|c|c|c|c|}
\hline No & Variabel & $\begin{array}{l}\text { Definisi } \\
\text { Operasional }\end{array}$ & Parameter & $\begin{array}{l}\text { Cara } \\
\text { Ukur }\end{array}$ & $\begin{array}{c}\text { Ska } \\
\text { la }\end{array}$ & $\begin{array}{l}\text { Alat } \\
\text { Ukur }\end{array}$ & Kategori \\
\hline 1. & $\begin{array}{l}\text { Vulva } \\
\text { hygiene }\end{array}$ & $\begin{array}{l}\text { Perawatan } \\
\text { diri WUS } \\
\text { untuk } \\
\text { memelihara } \\
\text { kebersihan } \\
\text { dan } \\
\text { kesehatan } \\
\text { daerah } \\
\text { kewanitaan }\end{array}$ & $\begin{array}{l}\text { 1. Mencuci daerah kewanitaan tiap kali } \\
\text { selesai BAB/BAK } \\
\text { 2. Mengeringkan daerah kewanitaan tiap } \\
\text { kali habis BAB/BAK } \\
\text { 3. Menganti pembalut minimal tiap } 5 \text { jam } \\
\text { sekali atau bila sudah dirasa perlu } \\
\text { 4. Mencuci daerah kewanitaan dari arah } \\
\text { depan kebelakang setiap habis } \\
\text { BABßBAK } \\
\text { 5. Saat membersihkan daerah kewanitaan } \\
\text { tidak memasukan jari atau air kedalam } \\
\text { liang sengama } \\
\text { 6. Tidak mengunakan sabun ataupun } \\
\text { cairan pembersih lain untuk } \\
\text { membersihkan daerah kewanitaan. } \\
\text { 7. Tidak mengunakan celana dalam yang } \\
\text { terlalu ketat/berbahan sintetis. } \\
\text { 8. Menganti celana dalam minimal } 2 \text { kali } \\
\text { sehari tom serta } \\
\text { 9. Kuku tangan bersih dan rapih } \\
\text { selalu mencuci tangan sebelum } \\
\text { menyentuh daerah kewanitaan. } \\
\text { 10. Merapikan dengan memotong bulu } \\
\text { kemaluan terutama saat menstruasi } \\
\text { agar tidak menempel disekitar vagian } \\
\text { untuk mencegah infeksi /iritasi }\end{array}$ & 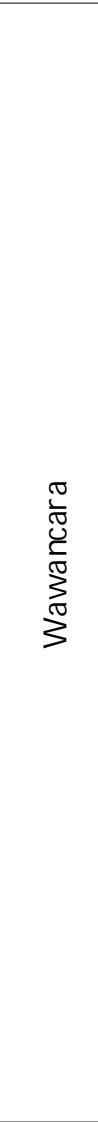 & $\begin{array}{l}\bar{\Xi} \\
\tilde{\Xi} \\
\tilde{0}\end{array}$ & 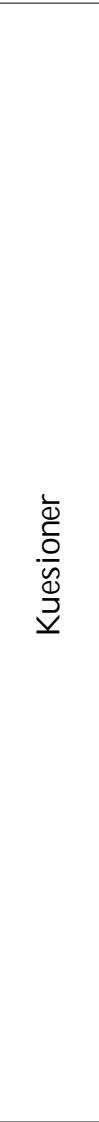 & $\begin{array}{l}\text { - Baik : } \\
76 \%- \\
100 \% \\
\text { - Cukup : } \\
56 \%-75 \% \\
\text { - Kurang } \\
\text { baik : } \\
<55 \%\end{array}$ \\
\hline 2. & $\begin{array}{l}\text { Kejadia } \\
\mathrm{n} \\
\text { Servisiti } \\
\mathrm{s}\end{array}$ & $\begin{array}{l}\text { Adanya } \\
\text { peradangan } \\
\text { pada serviks } \\
\text { uteri }\end{array}$ & $\begin{array}{l}\text { Gejala utama: } \\
\text { 1. Pembengkakan mulut rahim } \\
\text { 2. Pengeluaran cairan yang berlebihan, } \\
\text { 3. Mulut rahim terlihat merah karena } \\
\text { tanda-tanda infeksi atau ada iritasi } \\
\text { Gejala penunjang: } \\
\text { 1. Adanya rasa nyeri yang menjalar } \\
\text { kesekitar mulut rahim } \\
\text { 2. Dapat terjadi perdarahan saat } \\
\text { hubungan seks. }\end{array}$ & 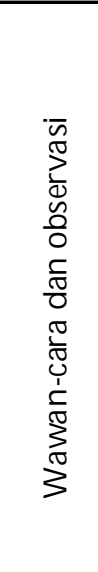 & 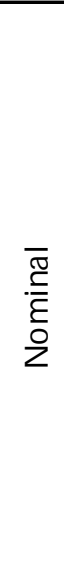 & 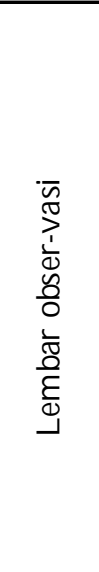 & $\begin{array}{l}\text { Positif } \\
\text { Servisitis : } \\
\text { minimal } \\
\text { ada } \\
\text { gejala } \\
\text { utama } \\
\text { Negatif } \\
\text { Servisitis : } \\
\text { tidak ada } \\
\text { satupun } \\
\text { gejala } \\
\text { utama } \\
\text { servisitis }\end{array}$ \\
\hline
\end{tabular}

Tabel 2

Perilaku vulva hygiene

di Desa Sambigede Kecamatan Sumberpucung Kabupaten Malang

\begin{tabular}{llll}
\hline No. & Vulva hygiene & Frekuensi & Prosentase $\mathbf{( \% )}$ \\
\hline 1 & Baik & 5 & 7.8 \\
2 & Cukup & 41 & 64.1 \\
3 & Kurang & 18 & 28.1 \\
\hline Total & & 64 & 100 \\
\hline
\end{tabular}


infeksi yang menjalar ke parametrium (Prawiroharjo, 2002). Penanganan terhadap infeksi ini harus dengan antibiotika dosis tepat dan menjaga kebersihan daerah kemaluan. Penyembuhan servisitis menahun sangat penting karena dapat menghindari keganasan yang merupakan pintu masuk infeksi ke alat kelamin bagian atas (Manuaba 2010).

Kejadian servisitis memang belum ada angka pasti yang menjelaskannya. Namun berdasarkan temuan di lapangan pada saat pemeriksaan IVA test pada acara bakti sosial di wilayah Puskesmas Sumberpucung Kabupaten Malang pada Februari 2011, dari 63 WUS yang diperiksa (tidak sedang haid) ternyata ditemukan 19 orang $(30,2 \%)$ yang mengalami tanda-tanda servisitis sehingga tidak dapat dilakukan pemeriksaan IVA test, dan harus dibersihkan serta diberikan pengobatan terlebih dahulu. Berdasarkan pengamatan lebih lanjut, diketahui dari 19 WUS yang mengalami gejala servisitis tersebut sebagian besar kebersihan dirinya kurang bagus, diantaranya terlihat pada saat dilakukan pemeriksaan, kebersihan genetalianya kurang yaitu daerah vulva tampak lembab dan tidak bersih, tampak keputihan yang banyak dan berbau serta celana dalam yang tampak lembab.

Berdasarkan data tersebut diatas, perlu dilakukan penelitian lebih lanjut untuk mengetahui hubungan antara vulva hygiene dengan kejadian servisitis, agar bidan nantinya dapat memberikan informasi yang tepat sehingga wanita usia subur dapat menjalani masa reproduksinya dengan sehat.

Penelitian ini bertujuan :

1. Mengidentifikasi vulva hygiene pada wanita usia subur di Desa Sambigede Kecamatan Sumberpucung Kabupaten Malang

2. Mengidentifikasi kejadian servisitis pada WUS di Desa Sambigede Kecamatan Sumberpucung Kabupaten Malang
3. Menganalisa hubungan antara Vulva hygiene dengan kejadian servisitis di Desa Sambigede Kecamatan Sumberpucung Kabupaten Malang.

\section{METODE PENELITIAN}

Dalam penelitian ini menggunakan desain penelitian korelasi yang bersifat analitik cross sectional untukmengidentifikasi hubungan antara Vulva hygiene dengan kejadian servisitis di Desa Sambigede Kecamatan Sumberpucung Kabupaten Malang. Pada penelitian ini sampel yang digunakan adalah $10 \%$ dari populasi wanita usia subur di wilayah Desa Sambigede Kecamatan Sumberpucung yaitu 639 orang, sehingga jumlah sampel yang diambil sebesar 64 responden. Prosedur yang digunakan dalam pengumpulan data vulva hygiene adalah dengan menggunakan angket yang langsung dibagikan kepada responden angket ini diisi oleh responden, angket langsung ditarik kembali oleh peneliti. Sedangkan pengumpulan data servisitis dilakukan dengan cara observasi kondisi serviks menggunakan lembar observasi / checklist. 


\section{ABSTRAK}

Kejadian servisitis memang belum ada angka pasti yang menjelaskannya. Namun berdasarkan temuan saat pemeriksaan IVA tes di wilayah Puskesmas Sumberpucung Kabupaten Malang pada Pebruari 2011, dari 63 WUS yang diperiksa (tidak sedang haid) ternyata ditemukan 19 orang (30,2\%) yang mengalami tanda-tanda servisitis. Berdasarkan pengamatan lebih lanjut, sebagian besar WUS tersebut kebersihan dirinya kurang bagus, diantaranya terlihat pada saat dilakukan pemeriksaan, kebersihan genetalianya kurang yaitu daerah vulva tampak lembab dan tidak bersih, keputihan yang banyak dan berbau serta celana dalam yang tampak lembab. Tujuan penelitian ini adalah untuk mengetahui hubungan vulva hygiene dengan kejadian servisitis. Desain penelitian ini adalah studi korelasional dengan pendekatan cross sectional. Populasi dalam penelitian ini adalah WUS Desa Sambigede RW I Kecamatan Sumberpucung Kabupaten Malang, sebanyak 639 orang. Sampel yang digunakan 10\% dari populasi dengan teknik purposive sampling sehingga didapat 64 responden yang memenuhi kriteria inklusi yang kemudian diberi kuesioner. Dari hasil penelitian yang dianalisis dengan Chi SquareTest didapatkan tingkat signifikasi 0,000 < nilai $\alpha 0,05$ maka $H_{0}$ ditolak yang berarti ada hubungan yang signifikan antara vulva hygiene dengan kejadian servisitis.

\section{Kata Kunci : Vulva hygiene, servisitis, IVA tes}

\section{PENDAHULUAN}

Vulva hygiene adalah salah satu kegiatan dari tindakan personal hygiene. Personal hygiene atau kebersihan perseorangan adalah suatu tindakan untuk memelihara kebersihan dan kesehatan diri seseorang untuk kesejahteraan fisik dan psikisnya. Macam-macam kegiatan personal hygiene diantaranya diantaranya perawatan gigi dan mulut, kebersihan kulit, kuku kaki dan tangan, termasuk pula perawatan genetalia. Kebersihan itu sendiri sangat dipengaruhi oleh nilai individu dan kebiasaan. Hal-hal yang berpengaruh itu diantaranya kebudayaan, sosial, keluarga, pendidikan, persepsi seseorang terhadap kesehatan serta tingkat perkembangan (Potter \& Perry, 2012).

Dalam kehidupan sehari-hari kebersihan merupakan hal yang sangat penting dan harus diperhatikan karena kebersihan akan mempengaruhi kesehatan dan psikis seseorang. Kebersihan itu sendiri sangat dipengaruhi oleh nilai individu dan kebiasaan. Jika seseorang sakit, biasanya masalah kebersihan kurang diperhatikan, hal ini terjadi karena kita menganggap masalah kebersihan adalah masalah sepele, padahal jika hal tersebut dibiarkan terus dapat mempengaruhi kesehatan secara umum (Prawiroharjo, 2002). Begitu pula kebersihan alat genetalia akan sangat berpengaruh terhadap kesehatan alat genetalia secara umum.

Pada wanita terdapat hubungan dari dunia luar dengan rongga peritoneum melalui vulva, vagina, uterus dan tuba falopii dan masingmasing alat traktus genetalis memiliki resiko untuk terkena infeksi. Servisitis atau radang pada serviks uteri terjadi pada sebagaian besar wanita terutama yang pernah melahirkan dan menjadi infeksi menahun yang sering tanpa disertai gejala-gejala atau keluhan yang jelas dari infeksi yang bersangkutan. Servisitis baru diketahui setelah dilakukan pemeriksaan yaitu porsio tampak kemerahan yang tidak dipisahkan secara jelas dari epitel porsio di sekitarnya, sekret yang dikeluarkan terdiri atas mukus bercampur nanah atau bahkan kadang-kadang serviks kelihatan normal dan baru diketahui setelah dilakukan pemeriksaan mikroskopik yaitu ditemukan infiltrasi leukosit dalam stroma endoserviks (Prawiroharjo, 2002).

Servisitis akut dapat disebabkan oleh gonokokus (gonorea) sebagai salah satu penyakit infeksi hubungan seksual. Pada infeksi setelah keguguran dan persalinan dapat disebabkan oleh stafilokokus dan streptokokus (Manuaba, 2010). Sekalipun organ genetalia memiliki pertahanan berlapis, infeksi dapat terjadi bila daya tahan tubuh mengalami kemunduran, atau kemampuan infeksi yang tinggi (seperti pada kebersihan diri yang jelek). Masuknya infeksi dapat terjadi melalui perlukaan yang menjadi pintu masuk saluran genetalia bagian luar maupun bagian tengah dan bagian atas, yang terjadi pada waktu persalinan atau tindakan medis yang menimbulkan perlukaan, atau terjadi karena hubungan seksual (Manuaba, 2009).

Infeksi serviks ini sering terjadi, akan tetapi biasanya tidak menimbulkan banyak gejala. Luka serviks yang dalam dan meluas dan langsung ke dasar ligamentum latum dapat menyebabkan 


\title{
HUBUNGAN ANTARA VULVA HYGIENE DENGAN KEJADIAN SERVISITIS DI DESA SAMBIGEDE KECAMATAN SUMBERPUCUNG KABUPATEN MALANG
}

THE CORRELATION BETWEEN VULVA HYGIENE WITH CERVICITIS

AT SAMBIGEDE VILLAGE, SUMBERPUCUNG DISTRICT,MALANG REGENCY

\author{
Ari Christiana ${ }^{1}$, dkk \\ Program Studi D-3 Kebidanan \\ STIKES Widyagama Husada
}

\begin{abstract}
There was no certain number which could explain about servicitis. According on the result of IVA test in Sumberpucung Public Health on February 2011 from 63 of productive women (non menstruation condition) it was found that 19 people had servicitis signs. Based on the next observation, most of productive women didn't keep clean theirselves such as the vulva was wet and dirty and the underwear was wet. The purpose of this research was to know the correlation of vulva hygiene and servicitis. The research design was correlational study with cross sectional approach. The population was productive women in sambigede RW.1 Sumberpucung, Malang 639 women. The sample was $10 \%$ of population with purposive sampling technique so it was got 64 respondents which fulfill the inclution criteria then they were given questionnaire. Based on the result which was analyzed by Chi Square Test, it was got signification $0,000<\alpha 0,05$ so $H_{0}$ was denied, it mean there was significant correlation between vulva hygiene and servicitis.
\end{abstract}

Keywords : Vulva hygiene, Servicitis, IVA test

\footnotetext{
Koento Martono ${ }^{2}$, Sri Rejeki ${ }^{3}$

Program Studi D-3 Kebidanan STIKES Widyagama Husada
} 